\title{
An investigation of the efficacy on hepatitis B vaccination in hemodialysis patients in Ardabil, Iran
}

\author{
Susan Mohammadi Kebar ${ }^{{ }^{*}}{ }^{\circledR}$, Saeed Hoseininia ${ }^{1}$, Yousef Mohammadi Kebar ${ }^{1}$, Mohammad Broumand $^{2}$ \\ ${ }^{1}$ Department of Internal Medicine, Ardabil University of Medical Sciences, Ardabil, Iran \\ ${ }^{2}$ Ardabil University of Medical Sciences, Ardabil, Iran
}

\section{A R T I C L E I N F O}

Article Type:

Original Article

Article History:

Received: 10 April 2018

Accepted: 26 July 2018

Published online: 20 August 2018

\section{Keywords:}

Vaccination

Hemodialysis

Hepatitis B

Renal failure

\begin{abstract}
A B S T R A C T
Introduction: Hemodialysis patients usually demonstrate lower immune response to hepatitis $B$ vaccine compared to non-uremic population.

Objectives: The present study aimed to determine the level of response to hepatitis $\mathrm{B}$ vaccination in patients under hemodialysis.

Patients and Methods: This study was conducted on 172 live patients receiving hemodialysis in the dialysis department of Buali hospital in Ardabil, Iran (2015). To analyze their response to the vaccine, their vaccination titers were investigated. Before vaccination, the serological markers of hepatitis $\mathrm{B}$ and $\mathrm{C}$ were checked in all of the patients. Those for whom HBsAg and $\mathrm{HBs} A \mathrm{~b}$ results were negative and had not received the vaccinein the past entered the study. The patients received a double dose of hepatitis $B$ vaccine at 0,1 , and 6 months after the beginning of dialysis. The response to the vaccine was investigated by measuring the level of patients' hepatitis $B$ antibody one month after receiving the last dose of the vaccine.

Results: Seventy patients ( $40 \%$ of the total) displayed a proper immune response to the vaccine, 34 patients $(19.8 \%)$ were without, and 68 patients $(39.5 \%)$ were identified to have poor response. The results of Pearson's correlation test indicated that there is a negative correlation between the patients' age and their response to the vaccine.

Conclusion: The results of this study indicated that higher age is one of the factors that reduce the effectiveness of hepatitis B vaccine in hemodialysis patients.
\end{abstract}

Implication for health policy/practice/research/medical education:

A study on 172 live patients receiving hemodialysis indicated that higher age is one of the factors that reduce the effectiveness of hepatitis $\mathrm{B}$ vaccine in hemodialysis patients.

Please cite this paper as: Mohammadi Kebar S, Hoseininia S, Mohammadi Kebar Y, Broumand M. An investigation of the efficacy on hepatitis B vaccination in hemodialysis patients in Ardabil, Iran. J Renal Inj Prev. 2019;8(1):6-10. DOI: 10.15171/jrip.2019.02.

\section{Introduction}

Hemodialysis patients are at higher risks of infection with hepatitis B virus compared to normal people (1). To prevent the spread of this infection in hemodialysis patients, the administration of hepatitis $B$ vaccine has been recommended. However, the response to the vaccine in these patients has been reported to be lower than healthy people (2).

In patients with advanced renal failure, there is a suppression of immune system due to uremia which results in a decrease in their response to the vaccine (3). Various factors have been found to affect the level of response to vaccines such as age, gender, nutritional status, the duration of dialysis, history of diabetes, dry weight, and hepatitis C antibody (4).
Patients with renal failure who have not yet reached the dialysis stage respond better to hepatitis B vaccination which shows the relationship between immune response and the level of renal failure (5). Various strategies have been proposed to increase the immune response to the vaccine in these patients. Among them are the addition of one extra dose of vaccination (4 doses) or doubling the dose of the vaccine $(40 \mu \mathrm{g})$. The employment of these methods has caused the level of seroconversion in patients to reach even $80 \%$ after taking the vaccine (6). However, there are paradoxes in different studies. That is why in this study we aimed to investigate the efficacy of double dose hepatitis $B$ vaccination and the factors affecting the response to it in hemodialysis patients in Ardabil, Iran. 
Objectives

The present study aimed to determine the level of response to hepatitis B vaccination in patients under hemodialysis.

\section{Patients and methods}

\section{Study population}

This study was conducted on all of the patients who were receiving hemodialysis maintenance since March 2015 in the dialysis department of Buali hospital in Ardabil. The effect of vaccination on them was investigated with reference to their records where in their antibody levels were recorded. Before dialysis, antibodies against hepatitis $\mathrm{B}$ and $\mathrm{C}$ were checked in all of the patients. Those for whom HBsAg and HBsAb results were negative and had not received the vaccine for hepatitis $B$ in the past entered to the study.

To collect information about the patients, a checklist was prepared and the information such as name, surname, age, gender, and diabetes history, serological profiles of hepatitis B, C and also body mass index (BMI) were recorded.

A double dose of hepatitis $B$ vaccine was administered to the patients in a 3-dose schedule at 0, 1 and 6 months after the beginning of dialysis. The response to the vaccine was investigated by measuring the patients' level of hepatitis $\mathrm{B}$ antibody one month after receiving the last dose of the vaccine. According to their $\mathrm{HBsAb}$ antibody level, the patients were divided into three groups as follows;

1. Patients without response (whose antibody levels were lower than $10 \mathrm{mIU} / \mathrm{mL}$ )

2. Patients with poor response (whose antibody levels were in the range of $10-100 \mathrm{mIU} / \mathrm{mL}$ )

3. Patients with proper response (whose antibody levels were higher than $100 \mathrm{mIU} / \mathrm{mL}$ ).

The antibody levels of each patient were recorded in their own checklist. Then, at the end of the study, the changes in serum HBsAb levels and their relationship with demographic factors were investigated. Patients who were receiving chemotherapy or consuming immunosuppressive drugs were excluded from the study.

\section{Ethical considerations}

This study was conducted following the Declaration of Helsinki principles. Informed written consent was obtained from each hemodialysis patient. The protocol of this study was approved by the Medical Ethics Committee of Ardabil University of Medical Sciences with the reference code of IR.ARUMS.REC.1394.62.

\section{Statistical analysis}

After collecting the data, they were coded and fed into SPSS Software version 19. Data analyzed using the inferential statistics of chi-square test, $t$ test, and Pearson's correlation test and reported in figures and tables using the descriptive statistical methods. In all instances, the significance level was set at 0.05 .

\section{Results}

In this study, 181 hemodialysis patients were selected to be studied. Nine of them were excluded because of receiving chemotherapy or consuming immunosuppressive drugs. As a result, 172 patients remained of whom 98 were male and 74 were female. The mean age of the remaining patients was $61.19 \pm 15.47$ years and most of them (45 patients constituting $26.2 \%$ of the total patients) were in the age range of 60-70 years. In this study, antibody against hepatitis $\mathrm{C}$ was not observed in the patients.

The statistical analysis of antibody titers against hepatitis $\mathrm{B}$ one month after the injection of the last dose of the vaccine indicated that 34 patients $(19.8 \%)$ have titers lower than $10 \mathrm{mIU} / \mathrm{mL}, 68$ patients (39.5\%) have titers in the range of $10-100 \mathrm{mIU} / \mathrm{mL}$, and 70 patients $(40.7 \%)$ have titers higher than $100 \mathrm{mIU} / \mathrm{mL}$ (Figure 1). Antibody titers were $25.62 \pm 4.74$ in males and $26.41 \pm 3.89$ in females, with no significant difference between two genders $(P=0.40)$.

On the other hand, the results of Pearson's correlation test indicated a negative correlation between patients' age and the level of titer induced by vaccination $(P=0.001, \mathrm{r}=$ -0.37). The negative value of correlation coefficient shows

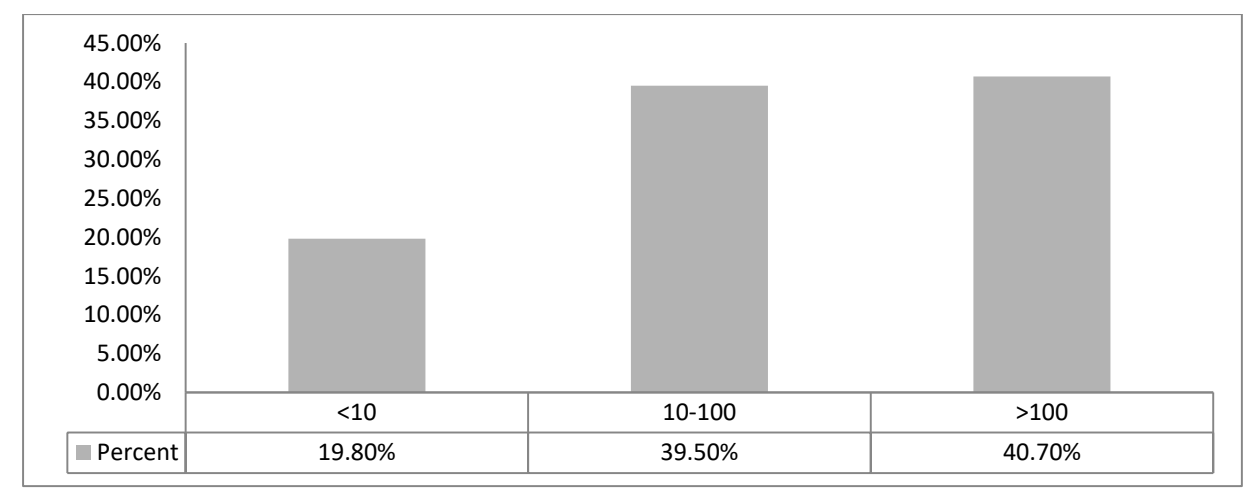

Figure 1. The distribution of patients based on the level of antibody titer against hepatitis B 1 month after the injection of the last dose of the vaccine. 
that as the patients' age increases, their level of antibody titer decreases.

The mean body mass index (BMI) of the patients in this study was $25.62 \pm 4.74 \mathrm{~kg} / \mathrm{m}^{2}$. The results of the analysis of BMI are presented in Table 1.

Around 76 patients $(44.2 \%)$ had diabetes and 32 patients $(18.66 \%)$ were smoker. The results indicated that there is no significant relationship between presence of diabetes or smoking and the level of response to the vaccine (Table 2).

\section{Discussion}

The results of the present study revealed no significant relationship exists between the patients' gender and the level of antibody titers induced as the result of hepatitis B vaccine. Similar to our finding, Navarro et al (4) also did not observe a significant relationship between the levels of immune titers in male and female hemodialysis patients after the injection of hepatitis B vaccine. In some studies, the response to the vaccine has been found to be higher in females compared to male patients and the concentration of anti-HBs antibody produced in females has been reported to be three times as much as that produced in males (7).

Pasco et al (8) investigated 111 hemodialysis patients. They observed a significant difference between males and females in their level of vaccination-induced immunity where the level of immunity in females was higher than that of males. However, it is not clearly known whether this difference in response is due to the difference in the body weight of the two genders or their sex hormones. In one study, this difference between males and females has been attributed to their body weight and it has been observed that when it is taken care of, the difference between the two groups in their response to vaccination no longer exists (9).

Our analysis in this study indicated that the effectiveness of vaccination significantly decreases as the age increases and older patients show lower response to the vaccine. In line with our finding, some studies have reported that patients under 40 years of age respond better to vaccination than those who are over that age (9). Similarly, Navarro et al (4) in their study revealed that as the age increases, the level of vaccination-induced immunity against hepatitis B in hemodialysis patients decreases. Peces et al (10) injected $40 \mu \mathrm{g}$ of the vaccine to patients in a 4 -dose schedule. They observed proper response in $77.5 \%$ of the patients $72.5 \%$ of whom had given a high immune response to the vaccination. They reported high response to vaccination in $100 \%$ of the patients under 40 and $74 \%$ of the patients over 60 years old.

In their follow-up of hemodialysis patients, Buti et al (11) observed that $41 \%$ of the patients lost their anti-HBs after 3 years. Those who had preserved their anti-HBs were younger and had higher levels of anti-HBs (11). This might be related to the decrease in immune system strength as the age increase which leads to a poor response to vaccination. According to the findings of the present
Table 1. Antibody titer regarding the different BMI levels

\begin{tabular}{lll}
\hline & & Antibody titer \\
\hline & $<19$ & $25.62 \pm 4.74$ \\
$\mathrm{BMI}\left(\mathrm{kg} / \mathrm{m}^{2}\right)$ & $19-25$ & $25.26 \pm 3.44$ \\
& $25-30$ & $24.35 \pm 4.52$ \\
& $>30$ & $34.68 \pm 3.12$ \\
\hline$P=0.35$ & &
\end{tabular}

Table 2. Antibody titer according to diabetes and smoking

\begin{tabular}{llcc}
\hline & & Antibody titer & P value \\
\hline \multirow{2}{*}{ Diabetes } & Yes & $24.65 \pm 4.14$ & \multirow{2}{*}{0.38} \\
& No & $25.49 \pm 3.28$ & \\
\multirow{2}{*}{ Smoking } & Yes & $25.12 \pm 3.02$ & \multirow{2}{*}{0.45} \\
& No & $25.88 \pm 4.00$ & \\
\hline
\end{tabular}

study, higher age is one of the factors that affect $\mathrm{HBsAb}$ titer. It decreases the efficacy of hepatitis $B$ vaccine which might be the result of the changes in the immune system of the body as people age (12).

According to the findings of the studies conducted by Pasco et al (8), Elwell et al (13), Katedra et al (14) and Ebrahim et al (15), no significant relationship was observed between the patients' age, gender, and HCV infection and the efficacy of hepatitis B vaccination for them. Moreover, Tele et al (16), Roozbeh et al (17) and Daco et al (18) indicated no significant relationship between age and the level of vaccination-induced immunity against hepatitis B. A possible reason for this finding might be the difference in the weight and gender of the patients under study.

The findings of our study demonstrated that there is no significant correlation between the patients' BMI and their response to the vaccine. Consistent with our findings, Daco et al (18), Tele et al (16), Roozbeh et al (17) and Ebrahim et al (15) did not find BMI of hemodialysis patients to be an effective factor in their response to hepatitis B vaccine. This lack of correlation can be attributed to the dependence of response to vaccination to multiple factors. In their study, Al Saran et al (12) found that gaining weight is a negative factor affecting the level of immunity induced as the result of hepatitis $\mathrm{B}$ vaccination in hemodialysis patients.

Our findings indicated that smoking and the vaccinationinduced immunity are not significantly related to each other. In line with our finding, no significant relationship was found between smoking and the level of vaccinationinduced immunity in the study by Al Saran et al (12). A possible reason for this finding might be the limited number of smokers included in this study.

In some studies, whose findings are inconsistent with ours, a decrease has been reported in smokers' anti-HBs response after getting vaccinated with hepatitis $B$ vaccine $(18,20)$. The probable mechanism for this result might be the effect of smoking on the reduction of immune response which, in turn, leads to a lower response to the vaccine. 
The findings of our study showed no significant relationship between having diabetes and the level of vaccination-induced immunity. In studies conducted by Al Saran et al (12), Daco et al (18), Tele et al (16), Roozbeh et al (17), and Peces et al (21), similar findings were reported which shows the consistency of our finding with them.

In another study, Fabrizi et al (22) found that the level of immunity induced as the result of hepatitis B vaccination is lower in hemodialysis patients suffering from diabetes compared to those without diabetes. Some of the factors that have been found to cause this difference are defective cellular immunity in diabetic patients (23), the reduction of B-lymphocyte cells and CD4/CD8 ratio of lymphocytes (24), and the impaired synthesis of antigens (25).

In all, the findings of our study indicated that in hemodialysis patients, gender, BMI, smoking, and having diabetes do not correlate significantly with the response to hepatitis B vaccine, while higher age significantly decreases its effectiveness.

\section{Conclusion}

Higher age was found to be one of the risk factors that decrease the efficacy of hepatitis $B$ vaccination in hemodialysis patients. Therefore, it is recommended that in patients with this risk factor more care be taken and more careful follow-ups be conducted over time.

\section{Limitations of the study}

The small proportion of patients included in this study was one the limitations of this research.

\section{Acknowledgments}

This study has been extracted from a thesis (Mohammad Broumand) conducted in Ardabil University of Medical Sciences. We hereby sincerely appreciate the vicechancellor and manager of the research office of the university, the members of the research council of the school of medicine, the staffs of the dialysis department, and all the patients who helped us to conduct this research.

\section{Authors' contribution}

All the authors have contributed towards performing the study and preparation of the manuscript and they all have approved the latest version of the article.

\section{Conflicts of interest}

The authors declare that they have no conflicts of interest in writing or publishing this research article.

\section{Ethical considerations}

Ethical issues (including plagiarism, data fabrication, double publication) have been completely observed by the authors.

\section{Funding/Support}

Ardabil University of Medical Sciences provided financial support for this research.

\section{References}

1. Wong PN, Fung TT, Mak SK, Lo KY, Tong GM, Wong Y, et al. Hepatitis B virus infection in dialysis patients. J Gastroenterol Hepatol. 2005;20:1641-51. doi: 10.1111/j.1440-1746.2005.03837.x

2. Sculamn G, Brenner BM. Hemodialysis, The kidney. 7th ed. Philadelphia: WB Sanders; 2004. p. 2563-15.

3. Taheri S, Shahidi S, Moghtaderi J, Seirafian S, Emami A, Eftekhari SM. Response rate to Hepatitis B vaccination in patients with chronic renal failure and end-stagerenal-disease: influence of diabetes mellitus. J Res Med Sci. 2005; 10:384-90.

4. Navarro JF, Teruel JL, Mateos ML, Marcen R, Ortuño J. Antibody level after hepatitis B vaccination in hemodialysis patients: influence of hepatitis C virus infection. Am J Nephrol. 1996;16:95-7. doi: 10.1159/000168977

5. Brown J, Peters V. Improved hepatitis B vaccination rates in ESRD patients in California. Adv Ren Replace Ther. 2000;7:S95-9.

6. Chin AI. Hepatitis B virus vaccine response in hemodialysis: baseline patient characteristics. Hemodial Int. 2003;7:296-303. doi: 10.1046/j.14927535.2003.00053.x.

7. Andre FE. Summary of safety and efficacy data on a yeastderived hepatitis B vaccine. Am J Med. 1989;87:14S-20S.

8. Pasko MT, Bartholomew WR, Beam TR Jr, Amsterdam $\mathrm{D}$, Cunningham EE. Long term evaluation of the hepatitis B vaccine in hemodialysis patient. Am J Kidney Dis. 1988;11:326-31.

9. Senden TF. Response to intradermal hepatitis B vaccination: differences between males and females? Vaccine. 1990;8:612-3.

10. Peces R, de la Torre M, Alcázar R, Urra JM. Prospective analysis of the factors influencing the antibody response to hepatitis B vaccine in hemodialysis patients. Am J Kidney Dis. 1997;29:239-45.

11. Buti M, Viladomiu L, Jardi R, Olmos A, Rodriguez JA, Bartolome $\mathrm{J}$, et al. Long-term immunogenicity and efficacy of hepatitis B vaccine in hemodialysis patients. Am J Nephrol. 1992;12:144-7. doi: 10.1159/000168436

12. Al Saran K, Sabry A, Al Halawany Z, Ismail M. Factors affecting response to hepatitis $\mathrm{B}$ vaccine among hemodialysis patients in a large Saudi hemodialysis center. Saudi J Kidney Dis Transpl. 2014;25:185-91.

13. Elwell RJ, Neumann M, Bailie GR. Factors associated with long-term antibody production induced by hepatitis B vaccine in patients undergoing hemodialysis: a retrospective cohort study. Pharmacotherapy. 2003;23:1558-63.

14. Katedra I, Rób Z. Efficacy of prophylactic vaccination against Hepatitis B Virus infection viruses in hemodialyzed patients. Przegl Epidemiol. 2000;54:34350 .

15. Ibrahim S, el-Din S, Bazzal I. Antibody level after hepatitis-B vaccination in hemodialysis patients: impact of dialysis adequacy, chronic inflammation, local endemicity and nutritional status. J Natl Med Assoc. 
2006; 98:1953-7.

16. Tele SA, Martins RM, Lopes CL, dos Santos Carneiro MA, Souza KP, Yoshida CF. Immunogenicity of a recombinant hepatitis B vaccine (Euvax-B) in haemodialysis patients and staff. Eur J Epidemiol. 2001;17:145-9.

17. Roozbeh J, Moini M, Lankarani KB, Sagheb MM, Shahpoori S, Bastani B. Low dose intradermal versus high dose intramuscular hepatitis $B$ vaccination in patients on chronic hemodialysis. ASAIO J. 2005;51:2425.

18. Dacko C, Holly J. The influence of nutritional status, dialysis adequacy, and residual renal function on the response to hepatitis B vaccination in peritoneal dialysis patients. Adv Perit Dial. 1996;12:315-7.

19. Hollinger FB. Hepatitis B virus. In: Fields BN, Knipe MD(ed) Virology. New York: Raven Press; 1996. p. 2739807.

20. Winter AP, Follett EA, Mcintyre J. Influence of smoking on immunological response to hepatitis $\mathrm{B}$ vaccine. Vaccine. 1994;12:771-2.

21. Peces R, Laures AS. Persistence of immunologic memory in long-term hemodialysis patients and healthcare workers given hepatitis $\mathrm{B}$ vaccine: role of a booster dose on antibody response. Nephron. 2001; 89:172-6. doi: $10.1159 / 000046064$

22. Fabrizi F, Dixit V, Martin P, Messa P. Meta-analysis: the impact of diabetes mellitus on the immunological response to hepatitis B virus vaccine in dialysis patients. Aliment Pharmacol Ther. 2011;33:815-21. doi: 10.1111/j.1365-2036.2011.04589.x.

23. Bouter KP, Diepersloot RJ, Wismans PJ, Gmelig Meyling FH, Hoekstra JB, Heijtink RA, et al. Humoral immune response to a yeast-derived hepatitis $B$ vaccine in patients with type 1 diabetes mellitus. Diabet Med. 1992;9:66-9.

24. Marseglia G, Alibrandi A, d'Annunzio G, Gulminetti R, Avanzini MA, Marconi M, et al. Long term persistence of anti-HBs protective levels in young patients with type 1 diabetes after recombinant hepatitis $B$ vaccine. Vaccine. 2000;19:680-3.

25. Marseglia GL, Scaramuzza A, d’Annunzio G, Comolli G, Gatti M, Lorini R. Successful immune response to a recombinant hepatitis $\mathrm{B}$ vaccine in young patients with insulin-dependent diabetes mellitus. Diabet Med. 1996;13:630-3.

Copyright (c) 2019 The Author(s); Published by Nickan Research Institute. This is an open-access article distributed under the terms of the Creative Commons Attribution License (http://creativecommons.org/licenses/by/4.0), which permits unrestricted use, distribution, and reproduction in any medium, provided the original work is properly cited. 